\title{
SEXUAL DEVIANCES
}

\author{
CRISTIAN DELCEA \\ Iuliu Hațieganu University of Medicine and Pharmacy, Cluj-Napoca, Romania \\ Sexology Institute of Romania, Cluj-Napoca, Romania
}

\begin{abstract}
Mental disorder is a significant behavioral or psychological syndrome or pattern that occurs in an individual and is associated with distress, impairment in functioning, or increased risk of suffering, death, pain, disability or an important loss of freedom. It is a manifestation of a behavioral, psychological or biological dysfunction in the individual. Socio-environmental factors can lead to an intellectually deficient individual to a deviant sexuality. Individuals with intellectual disabilities have problematic behaviour including, aggressive behaviour towards others and destructive acts. Some problematic behaviour include a sexual component.
\end{abstract}

Keywords: sexual deviances, mental disorder.

\section{INTRODUCTION}

\section{Legal conceptualizations}

Although psychological criteria for sexual devianceattend totheparticularsexual thoughts and behaviors of paraphiliacs, the law focuses on the effects of behavior on other people. Psychological criteria for sexual deviance include internal behaviors such as clinically significant distress and sexual fantasies. These do not enter into legal conceptualizations of deviancy. The legal system defines sexually deviant behavior by the details of the behavior and by the ages of the perpetrator and victim. At the point of sentencing, consequences of the aberrant behavior are also considered.

Specific categories of criminal sexual behavior vary from state to state, but most penal codes include:

- Rape

- Incest

- Communication with a minor for immoral purposes
- Sexual misconduct

- Child molestation

- Sodomy

- Oral copulation

- Penetration with a foreign object

- Indecent exposure

- Voyeurism

- Lewd or lascivious acts with a child

- Contributing to the delinquency of a minor

- Frotteurism

- Attempted sex offenses

\section{Intellectual disabilities and sexual education}

Individuals with intellectual disabilities often lack sexual knowledge(sexual health, safe practices, legal issues, contraception). Adequate sex education regarding these issues is needed to promote grater independence and reduce riscky behaviours.

Counterfeit deviance is defined as a false assesment of deviant behaviour resulting from influential factors. May come from different

*Corresponding author: 160 Plevnei Street, Cluj-Napoca, 400000, Romania, Phone/Fax: 0264 550247, email cristian.delcea.cj@gmail.com 
sources, such as inappropiate and unpunished sexual experiences, lack of adequate suport from the environment or inadequate education rather then actual deviant interests. Another theory says that can be attributed to lack of intimacy, inadequate learning, low socio-sexual skills or even side effects from medication.

To truly comprehend sexual deviance requires a suspention of belief that consts consideration of inconceivable.

Adult sexual assault is an essential focus of forensic psichology, variously diagnosed as sexual sadism, paraphilia or undiagnosed. Other forms of sexual deviance presented include voyeurism, exhibitionism, frotteurism, rape and pedophilia.

Voyeurism is the act of observing an unsuspecting person who is naked, in the process of disrobing, or engaging in sexual activity. Voyeurism has not been the target of treatment development independent of the other paraphilias. Therefore, all treatments for voyeurism should be considered experimental at this time. Case study reports indicate that treatment providers have used a variety of approaches to attempt to reduce the peeping of voyeurs. These include orgasmic reconditioning, aversion therapy, satiation, and drug therapy (fluoxetine).

Exhibitionism is the exposure of one's genitals to an unsuspecting stranger.

A variety of treatment techniques have been used with exhibitionists. There is no standard treatment for the disorder. Techniques with empirical and clinical support include:

\section{Treating Deviant Sexual Arousal}

- Aversive conditioning pairs an unconditioned aversive stimulus with a deviant response in order to reduce the likelihood of it occurring. Aversive stimuli have included electroshock, olfactory conditioning, covert sensitization, and vicarious sensitization. Covert sensitization involves relaxation, visualizing exposure scenes that produce deviant arousal, imagining negative consequences, and escape that is paired with not exposing. Vicarious sensitization involves viewing scenes of negative outcomes for sex offenders, some of them extreme.

- Conditioning procedures have included alternative behavior completion. This involves having the offender generate alternative behaviors for different points in the chain of behaviors that leads to offending. He imagines being caught up in that chain, enacting a behavioral alterative, and imagining how he would feel having escaped without reoffending.

- Biofeedback has been used as a treatment technique using the plethysmograph.

- Directed masturbation techniques have been useful with some exhibitionists. Specific approaches include fantasy change, masturbatory satiation, and directing the client not to masturbate to exposure fantasies. Fantasy change involves masturbating to deviant fantasies to nearly the ejaculation point and then switching to nondeviant fantasy. Masturbatory satiation involves masturbating to ejaculation using only nondeviant fantasies and continuing to fantasize after ejaculation, using deviant fantasies only in the flaccid state.

- Chemical castration through the use of medroxyprogesterone acetate (MPA) and cyproterone acetate (CPA) appears to be an effective treatment for exhibitionists through the reduction of the sex drive.

Frotteurism is touching and rubbing against a nonconsenting person. The special treatment needs of frotteurs are unknown and there are no treatment modalities that focus specifically on frottage. More general treatment approaches for the various paraphilias are described throughout this chapter. These are experimental methods of treatment that are being used with frotteurs. Frotteurism is a form of deviance with significant research and treatment development needs.

Sexual sadism is acts (real, not simulated) in which the psychological or physical suffering (including humiliation) of the victim is sexually exciting to the person. Treatment targets for sexual sadists include controlling deviant sexual arousal, increasing victim em- 
pathy, modifying cognitive distortions, and increasing social competency and balance in the lifestyle. Techniques for modifying deviant sexual arousal were described above. They include electroshock, olfactory aversion, covert sensitization, vicarious sensitization, masturbatory satiation and reconditioning, and chemical castration. Victim empathy training includes elements such as meeting with victims of sexual aggression, hearing audiotaped 911 calls from frantic victims, watching videos of victims describing their experiences, writing unsent letters to victims, and discussing personal victimization experiences while relating one's experience to the experience of other victims. Changing cognitive distortions involves the identification of distorted thinking and issuing challenges to those thoughts, typically in a group therapy format. Increasing social competency may mean different skills training for different offenders based on individual deficits. Some offenders may be inept in general communication. Others may have problems with assertiveness, intimacy, or anger, for example. Lifestyle balance also implies different needs for different offenders. Some offenders have problems with substance abuse, and others do not. Others may need treatment for other types of unbalanced behavior that establishes or maintains their deviance, such as viewing pornography, gambling, or isolating themselves from others. Established adjunctive treatments may be necessary to meet the unique needs posed by a particular presentation of sexually deviant behavior.

Pedophilia is sexual activity with a prepubescent child or children (generally age 13 or younger). The most popular treatments for pedophiles are cognitive-behavioral treatment (CBT) programs and antiandrogen interventions because they have the best reported outcomes (Grossman, Martis, \& Fichtner, 1999; Hall, 1995). See the meta-analyses by Furby, Weinrott, and Blackshaw (1989) and Rice, Quinsey, and Harris (1991) for the limitations of these interventions. Cognitive-behavioral treatments focus on altering deviant sexual arousal, changing offense-supportive envi- ronmental cues, finding alternative behaviors, and identifying/altering thoughts and feelings related to offending. Many of the approaches have been described earlier. The most popular combination treatment and maintenance program for sexual offenders in general, and pedophiles in particular, is the relapse prevention (RP) model (Laws, 1989; Pithers, 1990). Relapse prevention uses and extends the skills that are gained in sex offender treatment by helping the offender to recognize chains of internal and external events that led to each offense, identify high-risk situations that are related to those offense chains, recognize the short- and longterm consequences of offending behavior, and learn alternative coping skills in order to exit from the behavioral chain at any link prior to a relapse (Laws, 1989). The reader is directed to Remaking Relapse Prevention, edited by Laws, Hudson, and Ward (2000), for current, indepth information about RP for sexual offenders. The use of antiandrogens with pedophiles may be indicated if deviant sexual arousal is manifested, the offender is willing to participate in hormonal therapy, and there are no medical contraindications to the use of a pharmacological intervention.

Paraphilia is a general category for sexual behaviors that may be considered to be deviant but do not fit into one of the other categories of paraphilia. Behaviors may include telephone scatologia, necrophilia, and many others. Preference for sex with nonconsenting persons (rape) is often included in this classification.

Factors requiring treatment overlap for rapists and other sexual offenders. Important targets for treatment, depending on the idiographic offending pattern of the rapist, include denial and minimization, controlling deviant sexual arousal, victim empathy, cognitive distortions, understanding offending behavior chains, anger and stress management, and social skills training. A combination treatment approach including antiandrogen therapy and the appropriate cognitivebehavioral treatment components appears to be most promising. Hall (1995) conducted a meta-analysis of 12 treatment outcome studies that used a comparison 
or control group. He found that cognitive-behavioral and hormonal treatments produced larger effect sizes than strictly behavioral programs, larger effect sizes were found for studies that included higher recidivism base rates, and outpatient treatment studies fared better than those that focused on inpatient treatment. Hall found that over an average of 6.9 years at risk of reoffending, 19 percent of treated offenders and 27 percent of the comparison or control groups recidivated. More recently, in a key review of sex offender treatment outcome studies from 1970-1998, reported that the literature suggests a reduction in recidivism of 30 percent over seven years, with comparable effectiveness for hormonal and cognitive-behavioral treatments. They acknowledged that design flaws interfere with the accuracy of results in these studies, as other researchers have previously discussed. However, they conclude that these limitations are not a barrier to cautious interpretation of the available data. A problem with the treatment literature for rapists is that it is often the case that few rapists are included in the studies.

\section{CONCLUSION}

That is, they comprise a small subset of the sex offender group that is treated. Typically, treatment programs have been developed with child molesters and have been offered to rapists unchanged, or simply modified from their original version. Marshall (1993) proposed the idea that the real treatment needs of rapists have not been thoroughly researched but have been inadequately accommodated by existing approaches. One difficulty in studying rapists exclusively is that they are difficult to engage in treatment.

Funding Sources: This research did not receive any specific grant from funding agencies in the public, commercial, or not-for-profit sectors.

\section{REFERENCES}

1. Sbraga P. T., Sexual Deviance and Forensic Psichology: A Primer. Handbook of Forensic Psychology. Resource for Mental Health and Legal Professionals. 2004, Pages 429-470. Academic Press.

2. Boucher S., Comportements sexuels problématiques et déficience intellectuelle : étude d'un cas de déviance contrefaite Sexologies, Volume 23, Issue 4, October-December 2014, Pages 168172.

3. Christine M. Hunter, Christopher L. Hunter, Rodger Kessler (eds.)-Handbook of Clinical Psychology in Medical Settings. 2014. Springer

4. Heilbrun, K., Grisso, T., \& Goldstein, A., Foundations of forensic mental health assessment. 2008. New York: Oxford University Press. 